\title{
ECOLOGIA DA POLINIZAÇÃO DO MARACUJÁ-AMARELO, NA REGIÃO DO VALE DO SUBMÉDIO SÃO FRANCISCO ${ }^{1}$
}

\author{
KÁTIA MARIA MEDEIROS DE SIQUEIRA²,LÚCIA HELENA PIEDADE KIILL ${ }^{3}$, \\ CELSO FEITOSAMARTINS ${ }^{4}$, IVANICE BORGES LEMOS 5 , \\ SABRINA PITOMBEIRAMONTEIRO ${ }^{5}$, EDSÂNGELADEARAÚJO FEITOZA ${ }^{5}$
}

RESUMO-Este estudo descreve aspectos da biologia floral e sistema reprodutivo de Passiflora edulis f. flavicarpa (Passifloraceae), incluindo os padrões de forrageio e comportamento dos visitantes florais. O estudo foi desenvolvido em cultivo irrigado no Projeto Maniçoba, em Juazeiro-BA, em 2005/2006. A antese floral ocorreu entre $12 \mathrm{~h}$ e $13 \mathrm{~h}$, o fechamento da flor teve início às $18 \mathrm{~h}$, terminando por volta de $1 \mathrm{~h}$. $\mathrm{O}$ tempo para a deflexão dos estiletes foi de 71,4 $\pm 12,4$ min, mas cerca de 5\% das flores permaneceram com os estiletes sem curvatura. Os estigmas foram receptivos durante toda a antese, e os grãos de pólen apresentaram viabilidade de $94 \%$. O volume de néctar foi em média de $100 \mu \mathrm{L}$, com $48 \%$ de concentração de açúcares. O número médio de grãos de pólen/ flor foi de $140.595 \pm 34.175$, e $426 \pm 77$ óvulos/ ovário. As maiores taxas de frutificação $(74 \%)$ foram obtidas com polinização cruzada manual, confirmando a existência de sistema de autoincompatibilidade. Registraram-se $10 \%$ de flores com quatro estigmas que, quando polinizadas manualmente, apresentaram frutos maiores e com maior número de sementes $(477,7 \pm 76,8)$. Observou-se correlação positiva entre o número de sementes e o peso dos frutos. Os visitantes florais identificados foram Apis mellifera, Trigona spinipes, Xylocopa grisescens, X. frontalis e X. cearensis. As abelhas A. mellifera e T. spinipes foram pilhadores de pólen e néctar, respectivamente. As abelhas do gênero Xylocopa foram mais frequentes nas flores durante o período seco, e A. mellifera, durante o período chuvoso. Os polinizadores efetivos foram $X$. grisescens e $X$. frontalis, constatando-se uma limitação desses polinizadores nas áreas estudadas. Entretanto, eles foram mais frequentes em outras espécies vegetais no período chuvoso, indicando competição com as flores dos maracujazeiros pelos serviços de polinização.

Termos para indexação: Xylocopa frontalis, Xylocopa grisescens.

\section{ECOLOGY OF POLLINATION OF THE YELLOW PASSION FRUIT (PASSIFLORA EDULIS SIMS F. FLAVICARPA DEG.), IN THE REGION OF SÃO FRANCISCO VALLEY}

\begin{abstract}
This study describes aspects of floral biology and the reproductive system of Passiflora edulis f. flavicarpa (Passifloraceae), including foraging patterns of the floral visitors in the region of São Francisco Valley. The study was carried out in irrigated orchards in the Maniçoba Project, in Juazeiro-BA, during 2005 and 2006. The floral anthesis occurred between midday and $1 \mathrm{pm}$. Flower closing started at $6 \mathrm{pm}$ and finished around $1 \mathrm{am}$. The time for style deflexion was 71,4 $\pm 12,4 \mathrm{~min}$, about $5 \%$ of the flowers remained with the style undefexed. The stigmas were receptive during the entire anthesis and the pollen grains presented $94 \%$ viability. The nectar volume was in average $100 \mu \mathrm{L}$, with $48 \%$ of sugar concentration . The average number of pollen grains/flower was 140,595 $\pm 34,175$ and $426 \pm 77$ of ovules/ovary. The highest rates were obtained after manual crossed pollination (74\%), confirming the existence of a system of selfincompatibility. We registered $10 \%$ of flowers with four stigmas, which when manually pollinated, produced bigger fruits with a higher number of seeds $(477,7 \pm 76,8)$. We found a positive correlation between the number of seeds and the weight of the fruits. The flower visitors were Apis mellifera, Trigona spinipes, Xylocopa grisescens, X. frontalis and X. cearensis. A. mellifera and T. spinipes being pollen and nectar robbers, respectively. Bees of the genus Xylocopa were more frequent during the dry season and $A$. mellifera during the wet season. The effective pollinators were $X$. grisescens and $X$. frontalis. We found that they were limited in number in the studied areas. However they were found to be more frequent in other plant species during the rainy season which indicates that these plant species compete with the passion fruit for pollination service.

Index terms: Xylocopa frontalis, Xylocopa grisescens, breeding success, pollination service, Semi-Arid.

\footnotetext{
${ }^{1}$ (Trabalho 091-08). Recebido em: 11-04-2008. Aceito para publicação em: 24-10-2008.

${ }^{2}$ Dra. em Zoologia, Universidade do Estado da Bahia, Campus III, Juazeiro-BA, Cefet-Petrolina, katiauneb@yahoo.com.br ${ }^{3}$ Dra. em Biol. Vegetal, pesquisadora Embrapa Semi-Árido, kiill@cpatsa.embrapa.br

${ }^{4}$ Dr. em Zoologia, Departamento de Sistemática e Ecologia, Universidade Federal da Paraíba, cmartins@dse.ufpb.br

${ }^{5}$ Bolsistas - Apoio Técnico - AT/CNPq, Embrapa Semi-Árido.
} 


\section{INTRODUÇÃO}

O maracujazeiro (Passiflora edulis f. flavicarpa Deg.) pertence à família Passifloraceae, gênero Passiflora que compreende trepadeiras herbáceas ou lenhosas, de hastes cilíndricas ou quadrangulares, angulosas, suberificadas, glabras ou pilosas (Killip, 1938). No Brasil, existem cerca de 200 espécies do gênero Passiflora (Semir \& Brown, 1975). De acordo com Degener (1933), Passiflora edulis f. flavicarpa é semelhante a $P$. edulis f. edulis, diferindo deste táxon, por apresentar duas glândulas marginais nas sépalas mais externas, corona fortemente roxa na base e frutos maiores e amarelos. Quanto à antese floral, esta pode variar, entre os táxons ou formas, sendo que, no caso do maracujá-amarelo, as flores abrem depois do meio dia e fecham-se à noite, ou no início da manhã do dia seguinte (Cobert \& Willmer, 1980).

A frutificação do maracujá-amarelo é inteiramente dependente da polinização cruzada, em virtude da autoincompatibilidade (Bruckner et al., 1955), e a eficiência desse processo depende dos agentes polinizadores, no caso, espécies do gênero Xylocopa, conhecidas como mamangavas (Corbet \& Willmer, 1980; Sazima \& Sazima, 1989; Camillo, 2003).

Estudos sobre ecologia da polinização com P. edulis, foram desenvolvidos em outras regiões do País (Sazima \& Sazima, 1989; Varassin \& Silva, 1999; Oliveira, 2006; Gaglianone \& Hoffmann, 2006). Entretanto, estudos realizados em muitas culturas mostram diferenças na produção quando se comparam diferentes variedades em relação à polinização, como, por exemplo, café, citros, dentre outras (Klein et al., 2006). No Vale do Submédio São Francisco, região considerada como maior polo de fruticultura irrigada do País, as características existentes, como agricultura intensiva e as especificidades climáticas, devido a sua localização no ecossistema Caatinga, impõem a necessidade de estudos locais para subsidiar práticas de manejo que beneficiem os serviços de polinização. Nesta perspectiva, o presente trabalho teve como objetivos, estudar a biologia floral de $P$. edulis, os mecanismos de polinização e o sistema de reprodução, os padrões de comportamento dos visitantes florais nas estações seca e chuvosa, e a contribuição da polinização para o sucesso da cultura nessa região.

\section{MATERIAL E MÉTODOS}

As áreas selecionadas para os experimentos localizavam-se no Projeto de Irrigação Maniçoba, em Juazeiro (09²4"S 40²6"W), Bahia. O projeto conta com uma área de 4.293 ha, ocupada por 234 lotes de pequenos irrigantes, em 1.889 ha, e por 80 lotes de empresas, com 2.379 ha (CODEVASF, 2005). O clima é semiárido, a precipitação pluviométrica média anual é de $530 \mathrm{~mm}$, com as chuvas concentradas de novembro a abril (EMBRAPA, 2007) (Figura 1).

Para os estudos, foram definidas duas áreas de cultivo convencional, implantadas em novembro de 2003, com espaçamento de $2 \mathrm{~m}$ entre linhas e $3 \mathrm{~m}$ entre plantas, e com sistema de irrigação por sulcos. A primeira área (A) contava com 3 ha, e a segunda (B) com 6 ha, estando acerca de $5 \mathrm{~km}$ uma da outra. $\mathrm{A}$ área $\mathrm{A}$ foi considerada como área-controle, e a área B caracterizava-se por apresentar ninhos naturais (troncos de Commiphora leptophloeosBurseraceae com ninhos de Xylocopa spp.), com cerca de 800 fêmeas, introduzidos no cultivo pelo produtor.

Os experimentos foram desenvolvidos nas duas áreas, em 2005. Em 2006, estes foram realizados somente na área-controle, em virtude da infestação da outra área por fusariose (Fusarium oxysporum $\mathrm{f}$. sp. passiflorae).

Os horários de antese, receptividade do estigma, viabilidade dos grãos de pólen, volume e concentração do néctar foram observados ao longo da floração, bem como o tempo entre a antese e fechamento da flor. Após a abertura da flor, registrouse o tempo necessário para que os estiletes ficassem completamente curvos, isto é, com os estigmas no mesmo nível das anteras. Um total de 247 flores foi observado após as $15 \mathrm{~h}$, para identificação dos diferentes tipos florais quanto à curvatura e posicionamento dos estiletes. Para a quantificação do número de estigmas por flor, 100 flores foram amostradas no campo.

A receptividade do estigma foi testada em 20 flores com a aplicação de gotas de peróxido de hidrogênio $\left(\mathrm{H}_{2} \mathrm{O}_{2}\right)$ a 10 vol sobre a superfície estigmática (Zeisler, 1938), nos horários de 13h, 14h, $16 \mathrm{~h}$ e $18 \mathrm{~h}$.

Para obter-se o percentual de viabilidade, foram coletados cinco botões florais em pré-antese, armazenados em álcool a 70\%. Posteriormente, foi retirada uma antera por flor, esmagada em lâmina de vidro e corada com Carmim acético a 1,2\% (Radford et al., 1974). O tamanho dos grãos foi obtido, utilizando ocular micrométrica, sendo avaliados 10 grãos viáveis por lâmina.

Para estimar a quantidade de grãos de pólen produzidos por flor, anteras de flores diferentes $(\mathrm{n}=$ 
5) foram coletadas e armazenadas em álcool a 70\%, em volume conhecido (1,5 mL). Os grãos de pólen foram liberados por meio de agitação da solução, e, posteriormente, com pipeta calibrada, retiraram-se $100 \mu \mathrm{L}$ que foram depositados em lâmina de vidro. Após a evaporação do álcool, procedeu-se à contagem, fazendo-se, posteriormente, a proporção para o volume inicial (Kearns \& Inouye, 1993). Uma vez estimado o número de grãos por antera, este foi multiplicado por cinco para estimar o número de grãos produzidos por flor.

O número de óvulos foi quantificado em 20 ovários de flores com três estigmas e 10 ovários de flores com quatro estigmas, em observações diretas feitas em estereomicroscópio.

A quantificação do número de grãos de pólen depositados na superfície estigmática, após visita de abelhas do gênero Xylocopa, foi realizada por meio da coleta e acondicionamento individual desses estigmas $(n=10)$, em frasco com álcool a 70\%. Em laboratório, sob microscópio estereoscópico, procedeu-se à contagem dos grãos de pólen aderidos ao estigma. Para estimar os grãos que ficaram imersos no álcool, o volume restante da solução foi completado para $1,5 \mathrm{~mL}$, retirando-os após agitação $100 \mu \mathrm{L}$, que foram depositados em lâmina de vidro e analisados sob microscópio óptico. Após a contagem, foi realizada a proporção de grãos para 1,5 mL e, ao número resultante, foi acrescentada a contagem dos que estavam aderidos ao estigma.

Para avaliar o volume e a concentração do néctar, foram ensacados 10 botões florais em cada área, e, nos horários das $16 \mathrm{~h}$ e $18 \mathrm{~h}$, o néctar foi coletado, utilizando seringa de insulina. Em seguida, com o uso do refratômetro digital Atago N1 (0-50\%), foi medida a concentração de açúcares.

O percentual de frutificação da espécie foi avaliado por meio de polinizações manuais realizadas no campo. Para esses experimentos, botões em préantese foram emasculados e/ou ensacados e submetidos aos tratamentos de agamospermia ( $\mathrm{n}=$ 20), autopolinização manual $(n=30)$, polinização cruzada $(n=120)$, sendo os mesmos protegidos com sacos de papel após o tratamento.

Para realizar a polinização cruzada, flores com três estigmas foram submetidas à polinização em um, dois e nos três estigmas. No primeiro e segundo casos, os estigmas que não foram polinizados, foram excluídos das flores. A polinização cruzada também foi realizada em flores com quatro estigmas. Os frutos obtidos nos diferentes tratamentos foram avaliados quanto ao peso, formato (diâmetro e comprimento), número de sementes bem formadas e estimativas da concentração de açúcares ( ${ }^{\circ}$ brix).
Os visitantes florais foram observados ao longo de todo o período de floração do maracujazeiro, em dias não consecutivos, no período vespertino (12h30 às 17h30), sendo anotadas a frequência, duração e horário de suas visitas, o comportamento dos visitantes mais frequentes, bem como o recurso floral forrageado durante a visita.

De acordo com o comportamento apresentado, os visitantes foram considerados como polinizadores (Dafni, 1992) ou pilhadores (Inouye, 1980). Quanto à frequência, os visitantes foram classificados em: Abundantes (A), quando estes apresentavam frequências de visitas $\geq 30 \%$ do total de visitas registradas; Frequentes (F), quando apresentavam frequências de visitas de $\geq 10 \%<30 \%$, e Raros (R), quando apresentavam frequências $<10 \%$. Alguns visitantes foram capturados, fixados e mantidos a seco, para posterior identificação. Os visitantes coletados foram depositados no Laboratório de Ecologia da Embrapa Semiárido e duplicatas enviadas para o Laboratório de Entomologia da Universidade Federal da Paraíba.

Os registros foram feitos em pontos de observações, realizados por três observadores em 15 flores, nos meses de janeiro, fevereiro e outubro de 2005 e maio de 2006, com 22 repetições por intervalo de tempo, totalizando um esforço amostral de 110 horas de observações.

Para estimar o peso da carga polínica de operárias de A. mellifera $(\mathrm{n}=14)$ após visita às flores do maracujá, iniciaram-se a coleta e o acondicionamento das mesmas em frascos de 1,5 mL, com álcool a 70\%. Depois da retirada do pólen armazenado na corbícula e lavagem das abelhas para retirada do pólen aderido a outras partes do corpo, procedeu-se à pesagem dos grãos. Neste caso, foi utilizada uma balança analítica digital, onde um recipiente de vidro foi pesado, e, em seguida, foi vertido, no mesmo, o álcool contendo o pólen depreendido do corpo da abelha. Após a evaporação do álcool, realizou-se nova pesagem, obtendo-se, assim, o peso da carga polínica. O peso do pólen por antera $(n=10)$ foi obtido a partir de anteras colocadas, individualmente, em frascos com álcool a 70\%. Após agitação e consequente desprendimento dos grãos de pólen da teca, esta foi retirada, vertendo-se o conteúdo para um recipiente de vidro com peso previamente determinado e realizada a pesagem, de modo semelhante ao efetuado para determinar o peso da carga polínica.

A análise de variância das características dos frutos obtidos em diferentes tratamentos de polinização foi realizada utilizando-se o programa Statistica 6 (2003). As médias foram comparadas pelo 
teste de Tukey, ao nível de 5\% de probabilidade. Foi calculada, também, a correlação entre o peso dos frutos e o número de sementes bem formadas obtidas.

\section{RESULTADOS}

As flores de Passiflora edulis apresentamse isoladas, são hermafroditas, actinomorfas e pedunculadas, com androginóforo colunar, androceu formado por cinco estames, com filetes livres e inseridos abaixo do ovário; anteras dorsofixas, ovário globoso multiovular. O nectário é anular, abaixo do opérculo, com o límen (tecido que delimita a câmera nectarífera internamente) abaixo do androginóforo. O ovário é súpero e ovoide. De um total de 100 flores amostradas, observou-se que $10 \%$ apresentavam quatro estigmas.

O número médio de grãos de pólen por antera foi $28.119 \pm 6.835(n=5)$, sendo estimada a média de $140.595 \pm 34.175$ grãos por flor. Quanto ao tamanho, os grãos de pólen viáveis apresentaram 70,2 \pm 1,9 $\mu \mathrm{m}$. O número de óvulos, por ovário, encontrado nas flores da área- controle (A) foi 390,1 \pm 81,4 e $462 \pm$ 55,1 nas flores da área com ninhos (B) (Figura 2). As flores que apresentaram quatro estigmas, mostraramse funcionais. Nos ovários dessas flores, foram encontrados, em média, 674,5 \pm 105,7 óvulos.

A antese floral é diurna e sincrônica, com início da separação das sépalas, pétalas e filamentos da corona entre $12 \mathrm{~h}$ e $13 \mathrm{~h}$. As flores levam cerca de 10 minutos para abrirem. Nos dias nublados, verificouse que as flores começavam a abrir mais tarde. Após o início da abertura das flores, os filetes, antes eretos no botão, iniciam o movimento de curvatura para baixo. Nesta fase, também ocorre a movimentação das anteras, que ficam com face deiscente voltada em direção à corona e já com os grãos de pólen disponíveis. O movimento de curvatura durou, em média, $71,4 \pm 12,4 \mathrm{~min}$.

Os estigmas encontraram-se receptivos das $13 \mathrm{~h}$ às $18 \mathrm{~h}$, e, simultaneamente, os grãos de pólen estavam disponíveis nas anteras, apresentando viabilidade polínica média de $94 \%$.

$\mathrm{O}$ volume do néctar, por flor, foi semelhante nas duas áreas e nos dois horários de coleta $(100 \pm 4$ $\mu \mathrm{L}$ ) da mesma forma que a concentração de açúcares (47,3 $\pm 0,7^{\circ}$ brix).

Quanto à curvatura dos estiletes, foram registrados os percentuais de $4,8 \%$ e $5,7 \%$ de flores com estiletes sem curvaturas, $25,2 \%$ e $32,2 \%$ de parcialmente curvos e $70 \%$ e $62 \%$ de totalmente curvos nas áreas A e B, respectivamente.

A flor permanece inalterada até às $18 \mathrm{~h}$, quando se verificaram o murchamento e pequena alteração da coloração das pétalas e sépalas, tornando a flor menos atrativa. $\mathrm{O}$ fechamento total das flores ocorreu entre $24 \mathrm{~h}$ e $1 \mathrm{~h}$. Não havendo a fecundação, as flores murchavam e, no dia seguinte, caiam. O tempo entre a antese e o fechamento da flor foi de aproximadamente 12 horas, sendo o tempo efetivo para a polinização de aproximadamente 5 horas.

Os resultados da polinização natural, realizados nas áreas A e B, mostraram que, no período chuvoso, não foi registrada frutificação, porém observou-se $9,4 \%$ de formação de frutos no período seco (Tabela 1).

Quanto ao número de estigmas polinizados, observou-se que, nas flores em que um, dois, três ou os quatro estigmas receberam pólen, houve formação de frutos. Observou-se ainda que a formação de frutos foi maior nas flores com três estigmas, quando todos eles foram utilizados na polinização cruzada, porém naquelas em que foi feita a polinização em apenas um estigma, obteve-se a formação de um único fruto, totalmente deformado (Tabela 2). A quantificação do número de grãos de pólen aderidos a um estigma, após um único contato de Xylocopa spp., foi registrada, apresentando uma média de 1.624,2 \pm 499,7 grãos $(n=10)$.

Analisando os frutos oriundos de polinização cruzada manual em dois, três, quatro estigmas e polinização natural (controle), verificouse que houve diferenças entre o número de sementes bem formadas $[\mathrm{F}=8,20 ; \mathrm{Gl}=3,93 ; \mathrm{p}<0,01]$, peso $[\mathrm{F}=$ 22,72; $\mathrm{Gl}=3,93 ; \mathrm{p}<0,01]$, concentração de açúcares $[\mathrm{F}=26,38 ; \mathrm{Gl}=3,93 ; \mathrm{p}<0,01]$ e espessura da casca $[\mathrm{F}=14,46 ; \mathrm{Gl}=3-93 ; \mathrm{p}<0,01]$. Além disso, verificou-se que os frutos procedentes de polinização natural e os formados em flores com quatro estigmas polinizados manualmente diferiram significativamente dos demais frutos com relação ao peso e diâmetro.

No que diz respeito ao número de sementes, os frutos resultantes de flores com quatro estigmas polinizados apresentaram diferença significativa em relação aos demais (Tabela 3). Houve correlação positiva entre o peso dos frutos e o número de sementes bem formadas $(r=0,66 ; p<0,05)$.

Os visitantes identificados nas flores de $P$. edulis, durante as observações realizadas no primeiro semestre de 2005, foram: Xylocopa grisescens, X. frontalis, Apis mellifera e Trigona spinipes. No segundo semestre de 2006, além das espécies já citadas, registrou-se a presença de $X$. cearensis.

O comportamento de coleta de néctar nas flores do maracujazeiro, por machos e fêmeas de $X$. grisescens e $X$. frontalis, teve início com o pouso 
sobre a corona. Em seguida, dirigiam-se para a parte central da flor, onde se localiza a câmara nectarífera fechada acima pelo opérculo, firmemente ligado ao límen. Com suas mandíbulas, afastavam o opérculo, introduzindo a glossa para a coleta do néctar, permanecendo alguns segundos na mesma posição. Ao realizar deslocamentos, procurando novo acesso ao nectário, tocavam as anteras e os estigmas com a região dorsal do mesossoma, ficando o pólen aí depositado. Desse modo, o pólen era depositado no dorso de forma passiva.

Após a coleta de néctar, as abelhas saíam das flores, transportando grande quantidade de grãos de pólen aderidos à região dorsal do tórax, podendo voltar para a mesma flor e fazer nova coleta de néctar ou empreender novo voo à procura de outra flor, geralmente em outra planta. Quando outra Xylocopa se aproximava da flor anteriormente visitada, pairava no ar frente à mesma sem pousar, indicando que a flor poderia estar marcada com feromônios, e só a visitava após certo tempo. Já a espécie $X$. cearensis,por não apresentar porte compatível com a morfologia da flor, durante a atividade de coleta de néctar, apenas ocasionalmente tocava as partes reprodutivas das flores.

Durante o período chuvoso, na área-controle (A), observou-se que as abelhas Xylocopa visitavam plantas invasoras da cultura, que estavam em floração, destacando-se Crotalaria retusa, Phaseolus nathyroides e Dioclea grandiflora (Leguminosae). Em área de cultivo em repouso próximo à cultura do maracujá, no horário das $14 \mathrm{~h} 30$ às 16h, observou-se que estas abelhas estavam em intensa visitação nas flores da $C$. retusa, realizando coleta de néctar. Registraram-se visitas em 266 flores, num intervalo de $90 \mathrm{~min}(\mathrm{n}=10$ abelhas), permanecendo em média 5 segundos por flor.

Com relação ao comportamento de visita e recurso forrageado, observaram-se diferenças entre os visitantes florais. As operárias de T. spinipes, apesar de suas visitas serem raras (Tabela 4), apresentaram comportamento de roubo primário de néctar, perfurando a parte externa da câmara nectarífera, em visitas ilegítimas, uma vez que não conseguem afastar o opérculo para ter acesso ao néctar e também não tocavam o estigma.

As visitas de $A$. mellifera foram registradas no final da manhã, antes mesmo de completar- se o processo de antese, unicamente para retirada de pólen. Na coleta de pólen, pousavam diretamente nas anteras e, com as pernas médias e posteriores, fixavam- se em posição ventral em relação à antera. Agarradas às tecas com os últimos pares de pernas, coletavam o pólen com o primeiro par e auxílio do aparelho bucal. Após alguns minutos de coleta, saíam da flor e, no ar ou pousadas em uma folha, realizavam movimentos de limpeza, juntando o pólen aderido ao corpo e transferindo-o para as corbículas.

A comparação entre a média da carga de pólen retirada por A. mellifera $(20 \pm 20 \mathrm{mg})$ e a presente na antera de $P$. edulis $(7,8 \pm 4,1 \mathrm{mg})$ indica que estas abelhas podem retirar, em uma única visita, o equivalente ao pólen disponibilizado por duas anteras (Figura 3). Durante o tempo de permanência nas flores, $A$. mellifera não contata os estigmas, e a sua presença nas flores inibe a aproximação da Xylocopa.

Quanto à coleta de néctar, essas abelhas pousavam na parte inferior da flor, na região externa da câmara nectarífera, introduzindo o aparelho bucal em aberturas feitas por T. spinipes, caracterizando, assim, roubo secundário de néctar, pois não tocavam os estigmas.

Nas observações realizadas no período chuvoso, A. mellifera foi responsável por $95,5 \%$ das visitas na área sem ninho (A) e $98 \%$ na área com ninhos (B), enquanto as abelhas do gênero Xylocopa foram registradas apenas na segunda área, com $2 \%$ do número total de visitas. Já $T$. spinipes foi observada na área sem ninho (A), com 4,5\% de frequência (Tabela 4).

Entretanto, no período seco, observou-se uma inversão em relação à freqüência dos visitantes. As abelhas do gênero Xylocopa foram mais frequentes $(93,8 \%)$, enquanto $A$. mellifera $e T$. spinipes apresentaram frequências inferiores a $1 \%$. Nesta época do ano, X. cearensis foi observada, sendo responsável por $5,3 \%$ do total de visitas (Tabela 4).

Com relação ao horário de visitas, durante o período chuvoso, verificou-se que o maior número de visitas ocorreu entre $13 \mathrm{~h}$ e $15 \mathrm{~h}$, tendo como visitante mais frequente as operárias de $A$. mellifera. No período seco, observou-se que as abelhas do gênero Xylocopa estiveram presentes em todos os horários, destacando-se, com maior frequência, no final da tarde (Figura 4).

Com relação ao tempo de permanência na flor durante a coleta, as operárias de A. mellifera foram as que permaneceram mais tempo, cerca de 41 segundos, seguidas por Xylocopa spp. com média de 21 segundos.

Durante as observações de campo realizadas no período chuvoso, na área com ninhos naturais introduzidos (B), observou-se intensa atividade de nidificação de $X$. grisescens. Na entrada de alguns ninhos, foi registrada a presença de serragem. Além disso, no final da tarde, algumas 
fêmeas apresentavam comportamento típico de busca de novos locais para nidificação, inspecionando por meio de voos circulares, intercalados por pousos nos troncos e início de escavação, seguidos por novos voos ao redor de locais em potencial. Todavia, apesar da atividade de nidificação, poucos indivíduos visitaram as flores da cultura de maracujá nas proximidades.

\section{DISCUSSÃO}

As flores de $P$. edulis apresentam características adaptadas à polinização por abelhas de grande porte. A distância entre a face deiscente das anteras e a corola, a forma das anteras e o fato de elas serem versáteis, movimentando-se facilmente ao toque, permitem um acoplamento preciso na região dorsal de polinizadores maiores. Os estigmas, por sua vez, não apresentam movimentação, o que facilita a adesão do pólen quando tocado pela região dorsal da abelha.

Quanto ao tempo para deflexão dos estiletes, que resulta na posição adequada dos estigmas, para depositar pólen na região dorsal das abelhas de grande porte, Ruggiero \& Corrêa (1978) e Cereda \& Urashima (1989) registraram valores de 60 a $86 \mathrm{~min}$, sugerindo que essas diferenças podem ser atribuídas às condições climáticas regionais.

O mecanismo de deflexão dos estiletes estabelece, assim, uma barreira temporal para a polinização, mas não fisiológica, já que o pólen está disponível, e os estigmas, receptivos durante a antese (Benevides, 2006). Esta estratégia pode estar adaptada com o fluxo de pólen, uma vez que as abelhas começam a visitar as flores antes do posicionamento dos estigmas e, ao visitarem essas flores, poderão receber pólen de várias plantas, o que favoreceria a polinização cruzada. Assim, a eficiência da polinização das flores de $P$. edulis não está associada apenas às adaptações morfológicas das flores aos visitantes, mas também à sincronização temporal entre o horário de coleta das abelhas, abertura da flor e deflexão dos estiletes.

As flores cujos estiletes não sofrem deflexão, são consideradas funcionalmente masculinas, ocorrendo também em outras espécies de Passiflora, como P. foetida (Gottsberger et al., 1988), P. alata (Varassin \& Silva, 1999) e P. cincinnata (Kiill \& Siqueira, 2006). Em $P$. cincinnata, foram registradas flores com até cinco estigmas (Kiill \& Siqueira, 2006). No presente estudo, as flores com quatro estigmas mostraram-se funcionais. Segundo Janzen (1968), citado por Koschnitzke (1993), em Passiflora, a simetria trímera dos estigmas não é compatível com a simetria pentâmera das anteras. Na maioria das flores, um estigma não se encaixa entre duas anteras, permanecendo apoiado sobre o dorso de uma das tecas. Janzen (op. cit.) sugeriu hipóteses evolutivas para o aparecimento desses tipos florais.

Como esperado, por ser uma planta autoincompatível (Bruckner et al., 1995), existe a necessidade de polinização cruzada no maracujazeiro, sendo dependente de agentes polinizadores para sua reprodução. Segundo Akamine \& Girolami (1959), são necessários, no mínimo, 190 grãos de pólen para que ocorra a polinização no maracujá-amarelo. Por outro lado, Corbert \& Willmer (1980) comentam que há relação direta entre o tamanho do fruto e o número de sementes com o número de grãos de pólen depositados no estigma, independentemente do número de estigmas polinizados por flor. Os experimentos de polinização realizados neste estudo indicam que a polinização em um único estigma, independentemente do número de grãos depositados, pode determinar a formação de frutos, porém compromete a qualidade dos mesmos.

Os frutos produzidos a partir de flores polinizadas em quatro estigmas apresentaram diâmetro, espessura da casca, peso e número de sementes superiores aos outros tratamentos, indicando que flores que apresentam maior número de óvulos e que recebem maior número de grãos de pólen distribuídos de forma homogênea nos estigmas, produzem frutos de melhor qualidade.

Assim, Xylocopa grisescens e $X$. frontalis são os polinizadores efetivos da cultura na área estudada, por apresentarem vários atributos que favorecem a polinização cruzada, tais como dimensões compatíveis com a morfologia da flor, horário de visitação compatível com a deflexão dos estiletes e capacidade de transportar elevada quantidade de grãos de pólen e de depositá-los sobre os estigmas. A polinização nototríbica pelo pólen do dorso destas abelhas é realizada por machos e fêmeas.

As abelhas A. mellifera não contatam os estigmas e, ao promoverem a redução da disponibilidade de pólen, comprometem a polinização natural. Além disso, reduzem a possibilidade de visitas pelas abelhas de grande porte, uma vez que as flores que estão sendo visitadas por A. mellifera são evitadas por Xylocopa.

Trigona spinipes apresenta preferências por diferentes espécies de Passiflora, sendo considerada praga em algumas. Em experimento realizado na região do Semiárido, em Petrolina-PE, observou-se que as flores de $P$. cincinnata foram mais visitadas por elas $(19,7 \%)$ do que as de $P$. alata 
(5\%) e $P$. edulis (4,5\%). Nas flores de $P$. cincinnata, essas abelhas cortavam partes florais, principalmente os filamentos da corona, deixando as flores danificadas, pouco atrativas aos polinizadores efetivos (Kiill \& Siqueira, 2006). Em Jaboticabal-SP, foi registrada preferência marcante dessas abelhas por $P$. coccinea em relação a outras cinco espécies de Passiflora (Boiça Jr. et al., 2004). Quanto às injúrias causadas por $T$. spinipes em $P$. edulis, foi observado que elas não prejudicam o vingamento dos frutos, porém reduzem o número de óvulos fecundados, diminuindo assim, a percentagem da polpa (Silva et al., 1997).

No presente estudo, apesar da presença das duas espécies de Xylocopa como polinizadores efetivos, destacou-se o déficit de polinizadores observado na região, particularmente no período chuvoso. No período seco, os resultados da polinização natural $(9,4 \%)$ foram expressivos quando comparados com os registrados no período chuvoso, sendo que este percentual reflete exclusivamente a ação das abelhas do gênero Xylocopa na polinização. Além disso, apesar de o percentual ser inferior a $10 \%$, deve-se levar em consideração que, no momento de marcação dos botões amostrados, não foi possível identificar quais apresentavam os estiletes totalmente curvos. Assim, do total amostrado, cerca de $40 \%$ das flores apresentavam estiletes sem curvatura (SC), ou parcialmente curvos (PC), as quais não são polinizadas por abelhas mesmo quando visitadas. Dessa maneira, os resultados obtidos passam a ter maior significado com relação à ação dos polinizadores, já que, com o número corrigido de flores aptas à polinização, a polinização natural passa de $9,4 \%$ para $15,6 \%$. Todavia, esses valores ainda indicam uma limitação de polinizadores, mesmo no período seco. Segundo Ruggiero (1987), taxas de frutificação do maracujá, sob condições naturais, para serem consideradas boas, deveriam estar entre 40 e $50 \%$. Em estudo realizado em Cruz das Almas-BA, verificou-se uma variação nas taxas de sucesso reprodutivo com a polinização natural de $11,8 \%$ a $52,3 \%$, sendo esta quantificada três vezes, em um período de apenas quatro dias, indicando que, mesmo sob condições semelhantes, o percentual de frutificação pode variar (Rojas \& Medina, 1996).

No período chuvoso, a influência da localização dos ninhos naturais dentro do cultivo não se mostrou relevante, uma vez que a ausência de frutificação foi observada nas duas áreas, com e sem a introdução de abelhas do gênero Xylocopa. Nesse período, foi registrada a atração por flores de outras espécies, tais como da família Leguminosae. Por exemplo, em estudo realizado em outra área de
Caatinga, em Serra Negra-RN, observou-se que plantas do gênero Crotalaria eram visitadas quase que exclusivamente por $X$. grisescens (Zanella \& Martins, 2003). Estes dados indicam que a presença dessas plantas na cultura ou no seu entorno, deslocam o forrageio dessas abelhas, reduzindo a possibilidade de polinização nas flores do maracujá no período chuvoso. Além disso, de acordo com Silva et al. (1999), o aumento da umidade reduz a densidade populacional das abelhas Xylocopa, sendo que o inverso ocorre com o aumento da insolação.

Por outro lado, a abundância das abelhas $A$. mellifera, na estação chuvosa, está associada à intensa atividade dessas abelhas nessa estação e sua atração pelo pólen do maracujazeiro. Nesse período, as colônias de A. mellifera apresentam desenvolvimento populacional, necessitando de maiores quantidades de pólen.

Durante a estação seca, as abelhas do gênero Xylocopa encontram, na cultura do maracujá, maior disponibilidade de néctar em relação à floração da caatinga e, assim, são atraídas para a área. Por outro lado, na Caatinga, as abelhas A. mellifera apresentam redução nas suas atividades de forrageio e aprovisionamento de alimento, devido às temperaturas elevadas, baixa umidade e menor oferta de recursos, determinando, assim, redução do número de visitas neste período (Zanella \& Martins, 2003).

A influência na disponibilidade de recursos no entorno gera um quadro característico para a área estudada. No período seco, com a floração nativa reduzida, as espécies de Xylocopa encontram oferta alternativa de alimento na cultura, ocorrendo aumento no número de visitas. Todavia, na estação chuvosa, a vegetação nativa compete com a cultura, como também as plantas invasoras do cultivo, deslocando o forrageio dos polinizadores. Desse modo, a conservação de hábitats, naturais ou seminaturais no entorno, garante a permanência dos polinizadores, disponibilizando recursos e servindo de abrigo para as abelhas. Segundo Klein et al. (2006), a existência dessas áreas é de grande importância, principalmente em culturas polinizadas por um número restrito de espécies, como é o caso de $P$. edulis.

Assim, pode-se concluir que a presença dos polinizadores efetivos do maracujá-amarelo, $X$. grisescens e $X$. frontalis, não está relacionada apenas à localização dos ninhos, mas também a outros aspectos da ecologia da espécie, como atratividade das plantas, a disponibilidade de recursos e a competição entre espécies vegetais pelos 
polinizadores, o que demanda um manejo adequado do ambiente. Como alternativa, seria útil testar o uso

no período chuvoso. de substâncias atrativas nas culturas de maracujá

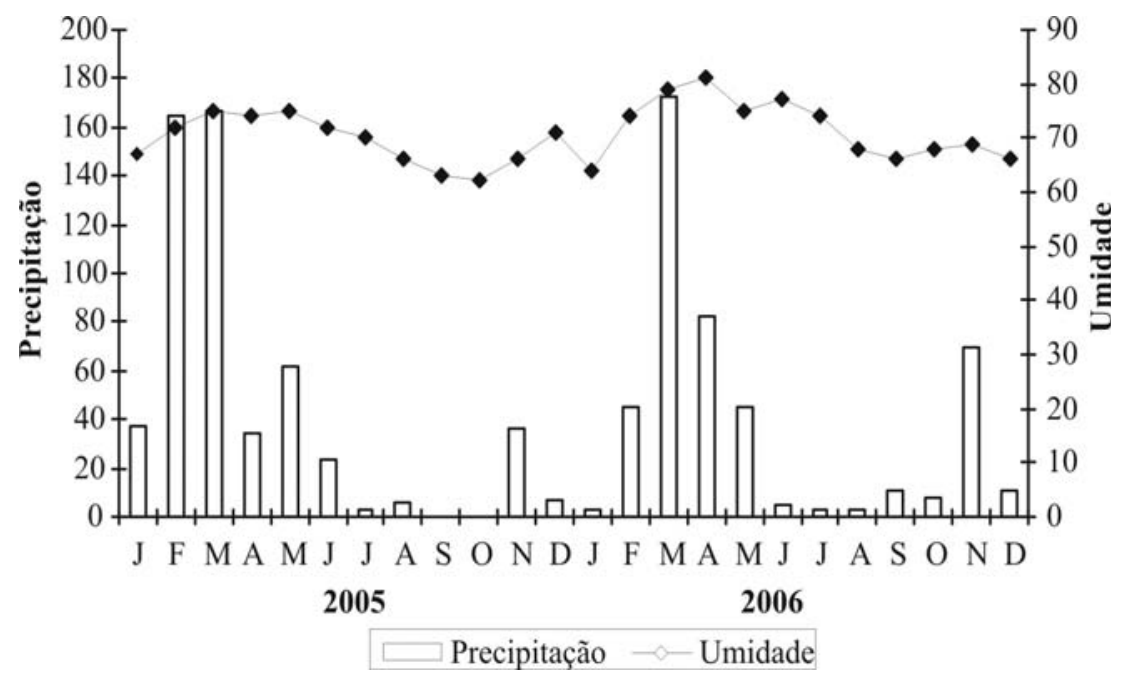

FIGURA 1 - Médias mensais de precipitação e umidade obtidos da Estação Meteorológica da Embrapa Semiárido, localizada no Projeto Mandacaru, em Juazeiro (09²4"S 40²6"W), Bahia, durante os anos de 2005 e 2006.

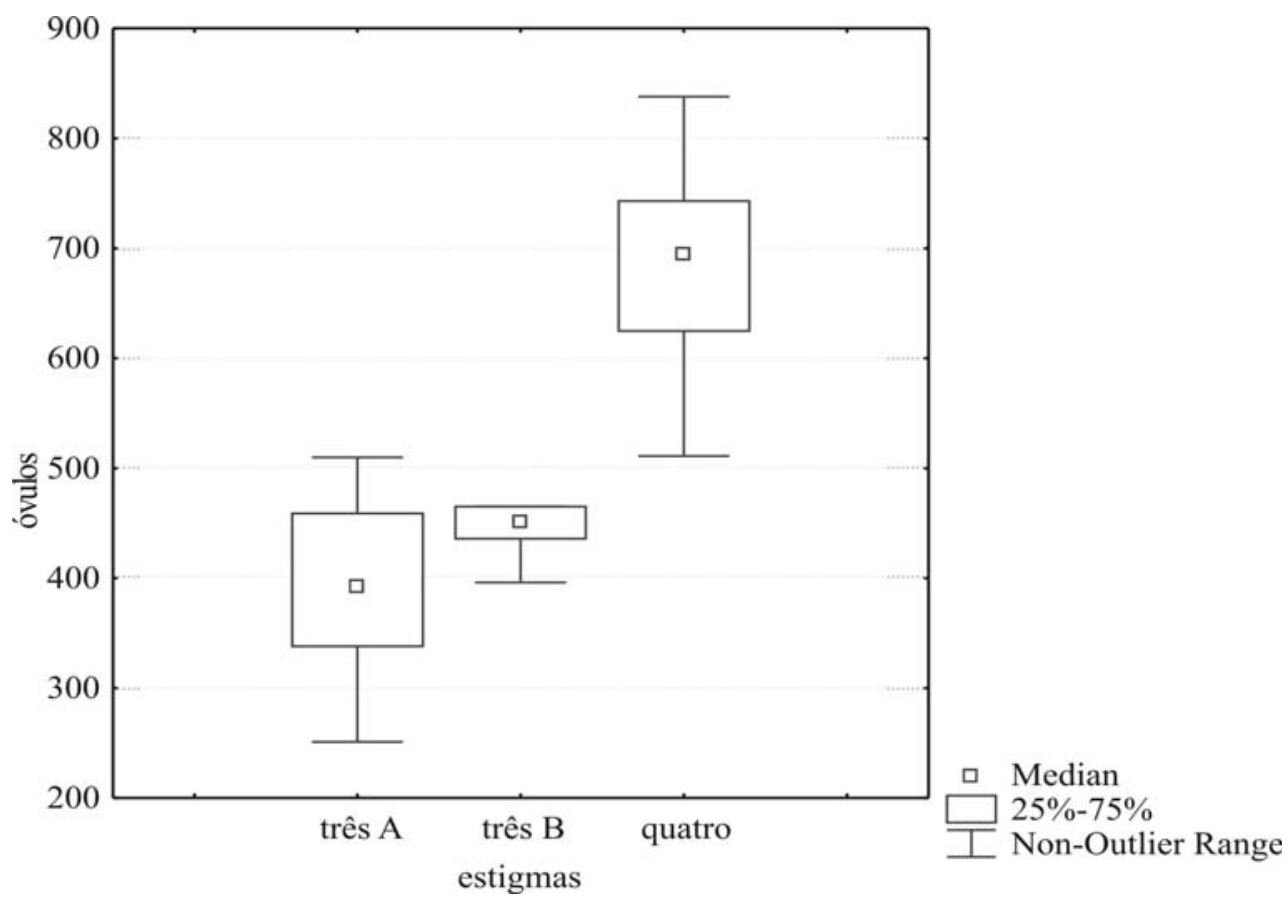

FIGURA 2 - Comparação entre as médias e desvio-padrão do número de óvulos registrados em flores com três estigmas (áreas A e B) e flores apresentando quatro estigmas (área A). 


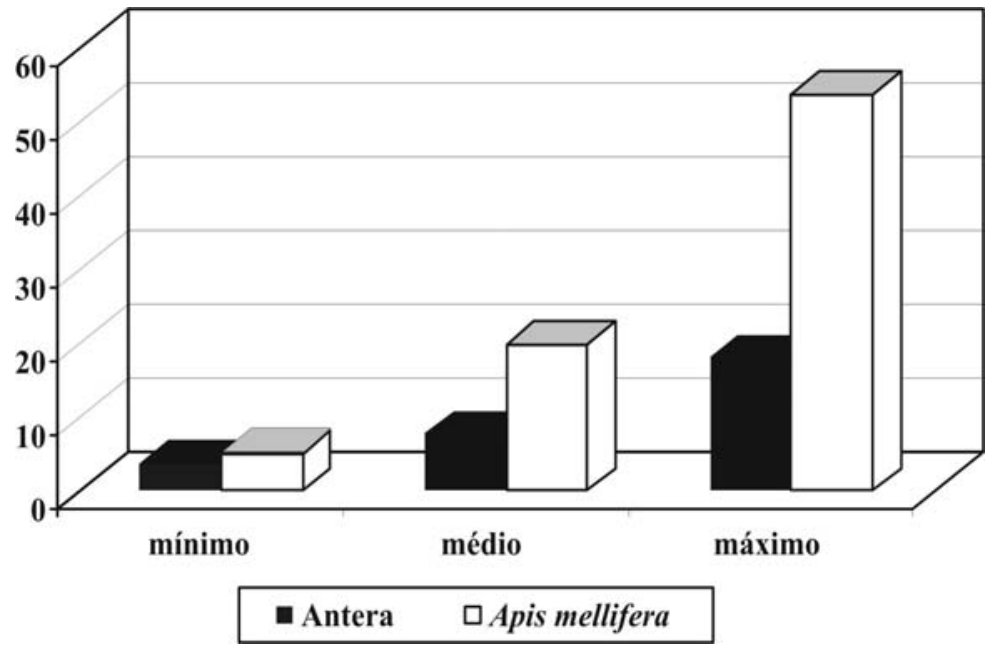

FIGURA 3 - Comparação entre os valores mínimo, médio e máximo do peso da carga polínica de uma antera de Passiflora edulis e da encontrada no corpo de Apis mellifera.

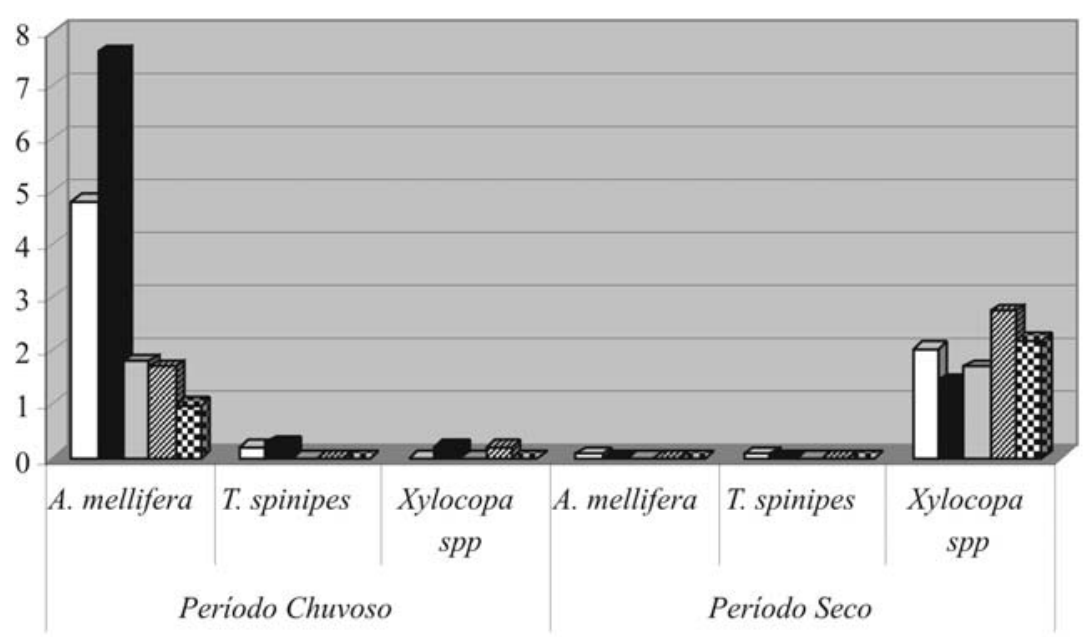

\section{$13 \mathrm{~h} / 14 \mathrm{~h} \quad \mathbf{1 4 h} / 15 \mathrm{~h} \quad \square 15 \mathrm{~h} / 16 \mathrm{~h} \quad$ 圆 $16 \mathrm{~h} / 17 \mathrm{~h} \quad \mathbf{0} 17 \mathrm{~h} / 18 \mathrm{~h}$}

FIGURA 4 - Número médio de visitas por intervalo de tempo, durante as estações chuvosa e seca, em cultivo irrigado de P. edulis, no Projeto Maniçoba, Juazeiro-BA, nos anos de 2005/2.

TABELA 1 - Experimentos sobre o sistema reprodutivo e formação de frutos realizados na cultura do maracujá-amarelo (P. edulis), em duas áreas de cultivo, no Projeto Maniçoba, Juazeiro-BA., nos anos de 2005/2006.

\begin{tabular}{lcccccc}
\hline \multirow{2}{*}{ Tratamentos } & \multicolumn{4}{c}{ Área A } & \multicolumn{2}{c}{$\begin{array}{c}\text { Área B } \\
\text { Período chuvoso }\end{array}$} \\
\cline { 2 - 6 } & \multicolumn{2}{c}{ Período chuvoso } & Período seco & \multicolumn{2}{c}{ Pl/Fr } & $\%$ \\
\cline { 2 - 6 } & Fl/Fr & $\mathbf{\%}$ & Fl/Fr & $\%$ & \% \\
\hline Polinżação natural (controle) & $60 / 0$ & 0 & $330 / 31$ & 9,4 & $60 / 0$ & 0 \\
Agamospermia & $20 / 0$ & 0 & - & - & - & - \\
Autopolinização manual & $30 / 0$ & 0 & - & - & - & - \\
Polinização cruzada manual & $60 / 44$ & 74 & - & - & $60 / 38$ & 63 \\
\hline
\end{tabular}

$\mathrm{Fl} / \mathrm{Fr}=$ flores frutos

$\%$ Porcentagem de frutificação 
TABELA 2 - Flores submetidas à polinização natural (PCN3) e cruzada manual em 1; 2; 3 e 4 estigmas (PCM) com os respectivos números e porcentagens de vingamento dos frutos, no maracujá-amarelo (P. edulis f. flavicarpa Deg.).

\begin{tabular}{lccc}
\hline \multicolumn{1}{c}{ Tratamentos } & $\begin{array}{c}\text { Número de } \\
\text { flores (n) }\end{array}$ & $\begin{array}{c}\text { Número de } \\
\text { frutos (n) }\end{array}$ & $\begin{array}{c}\text { Sucesso } \\
\%\end{array}$ \\
\hline Controle (PCN3) & 330 & 31 & 9,4 \\
1 estigma (PCM1) & 10 & 1 & 10 \\
2 estigmas (PCM2) & 40 & 20 & 50 \\
3 estigmas (PCM3) & 60 & 46 & 78 \\
4 estigmas(PCM4) & 21 & 9 & 42,8 \\
\hline
\end{tabular}

TABELA 3 - Média e desvio-padrão das medidas de avaliação dos frutos do maracujá-amarelo (P. edulis), submetidos aos seguintes tratamentos; polinização cruzada manual (PCM) em quatro, três, e dois estigmas, e polinização natural (PCN-3-controle).

\begin{tabular}{|c|c|c|c|c|}
\hline \multirow{2}{*}{$\begin{array}{c}\text { Característica dos } \\
\text { frutos }\end{array}$} & \multicolumn{4}{|c|}{ Passiflora edulis } \\
\hline & PCN-3 $(n=26)$ & PCM-2 $(n=18)$ & PCM-3 $(n=43)$ & PCM- $4(n=9)$ \\
\hline Peso (g) & $229,24 \quad 53,7 \mathbf{a}$ & $160,33 \pm 58,1$ a b & $166,65 \pm 48,8 \mathbf{b}$ & $301,75 \pm 71,06 \mathbf{c}$ \\
\hline Comprimento (mm) & $92,98 \quad 6,76 \mathbf{a}$ & $98,86 \pm 12,61 \mathbf{a}$ & $83,61 \pm 9,0 \mathbf{a}$ & $91,98 \pm 16,41 \mathbf{a}$ \\
\hline Diâmetro (mm) & $0,01 \mathbf{a}$ & $75,48 \pm 10,78 \mathbf{b}$ & $72,76 \pm 7,89 \mathbf{b}$ & $93,62 \pm 8,69 \mathbf{a}$ \\
\hline Espessura da casca $(\mathrm{mm})$ & $12,11 \pm 1,15 \mathbf{a}$ & $7,50 \pm 1,01 \mathbf{a}$ & $9,99 \pm 2,63 \mathbf{a}$ & $14,80 \pm 3,95 \mathbf{b}$ \\
\hline Brix $(\%)$ & $10,65 \quad 3,04 \mathbf{a}$ & $13,96 \pm 2,53 \mathbf{b}$ & $8,86 \pm 1,84 \mathbf{c}$ & $9,27 \pm 1,30$ a c \\
\hline Sementes $\left(n^{\circ}\right)$ & $311 \quad 16,97 \mathbf{a}$ & $320,94 \pm 112,3 \mathbf{a}$ & $265,27 \pm 123,4 \mathbf{a}$ & $477,77 \pm 76,83 \mathbf{b}$ \\
\hline Sementes inviáveis $\left(\mathrm{n}^{\mathrm{0}}\right)$ & $3,53 \mathbf{a}$ & $16,26 \pm 27,86 \mathbf{a}$ & $33,51 \pm 53,82 \mathbf{a}$ & $29 \pm 25,86 \mathbf{a}$ \\
\hline
\end{tabular}

Médias na mesma linha, acompanhadas de mesma letra, não diferem significativamente entre si, ao nível de 5\% de probabilidade, pelo teste de Tukey.

TABELA 4 - Visitantes florais de $P$. edulis com seus respectivos números de visitas, percentagem, classe de frequência, recurso floral utilizado e resultado da visita, nas áreas A e B, no primeiro semestre de 2005, e área A, no segundo de 2006. Classes de frequência: $A=$ Abundante $(>30 \%), F=$ Frequente (e" 10 d" $30 \%$ ) e R = Raro $(<10 \%)$.

\begin{tabular}{|c|c|c|c|c|c|c|c|c|c|c|c|}
\hline \multirow{3}{*}{ Visitantes } & \multicolumn{6}{|c|}{ Área A } & \multirow{2}{*}{\multicolumn{3}{|c|}{$\frac{\text { Área B }}{\text { Período chuvoso }}$}} & \multirow{3}{*}{ Recurso } & \multirow{3}{*}{$\begin{array}{l}\text { Resultado } \\
\text { da visita }\end{array}$} \\
\hline & \multicolumn{3}{|c|}{ Período chuvoso } & \multicolumn{3}{|c|}{ Período seco } & & & & & \\
\hline & № & $\%$ & F. & $\mathbf{N}^{\mathbf{0}}$ & $\%$ & F. & N No & $\%$ & F. & & \\
\hline A.mellifera & 105 & 95,5 & $\mathrm{~A}$ & 1 & 0,3 & $\mathrm{R}$ & 96 & 98 & $\mathrm{~A}$ & $\mathrm{P} / \mathrm{N}$ & $\begin{array}{c}\text { Furto } \\
\text { Roubo } 2^{\text {ário }}\end{array}$ \\
\hline T. spinipes & 5 & 4,5 & $\mathrm{R}$ & 2 & 0,6 & $\mathrm{R}$ & - & - & - & $\mathrm{N}$ & Roubo $1^{\text {ário }}$ \\
\hline Xylocopa spp. & - & - & - & 285 & 93,8 & A & 02 & 2 & $\mathrm{R}$ & $\mathrm{N}$ & Polinizador \\
\hline$X$. cearensis & - & - & - & 16 & 5,3 & $\mathrm{R}$ & - & - & - & $\mathrm{N}$ & $\begin{array}{c}\text { Polinizador } \\
\text { ocasional }\end{array}$ \\
\hline Total & 110 & 100 & & 304 & 100 & & 98 & 100 & & & \\
\hline
\end{tabular}

$\mathrm{P}=$ pólen; $\mathrm{N}=$ néctar

Roubo primário= quando causa danos às flores, Roubo secundário= quando para coletar néctar utiliza as aberturas feitas no nectário por outra espécie; Furto= retirada dos recursos florais sem danos às flores e sem polinização (Inouye !980). 


\section{CONCLUSÕES}

1-Foi registrado um déficit de polinizadores na região, principalmente no período chuvoso, quando a vegetação do entorno compete com a cultura.

2-No período chuvoso, as abelhas Apis mellifera reduzem a disponibilidade de pólen, comprometendo os serviços de polinização.

3-Os frutos originados de flores com quatro estigmas apresentam diâmetro, espessura da casca, peso e número de sementes superiores às flores com três estigmas.

\section{AGRADECIMENTOS}

Ao PROBIO/MMA/GEF, pelo apoio financeiro durante o desenvolvimento do projeto "Diagnóstico de polinizadores no Vale do São Francisco"; ao CNPq, pela concessão das bolsas de Apoio Técnico; à UNEB, pela concessão de bolsa de estudo (PAC) à primeira autora ,e aos produtores de maracujá do Projeto Maniçoba, pela disponibilidade da área experimental e informações concedidas.

\section{REFERÊNCIAS}

AKAMINE, E. K.; GIROLAMI, G. Pollination and fruit set in the yellow passion fruit. Agricultural Experiment Station, Honolulu: University of Hawaii, 1959. 44p. (Technical Bulletin, 39).

BENEVIDES, C. R. Biologia floral e polinização de passifloraceae nativas e cultivadas na região norte Fluminense-RJ. 2006. 88 f. Dissertação (Mestrado) Universidade Estadual do Norte Fluminense, Campos dos Goytacases, 2006.

BOIÇA JR., A. L.; SANTOS, T. M.; PASSILONGO, J. Trigona spinipes (Fabr.) (Hymenoptera: Apidae) em espécies de maracujazeiro: flutuação populacional, horário de visitação e danos às flores. Neotropical Entomology, Piracicaba, v. 33, n. 2, p. 135-139, 2004.

BRUCKNER, C. H.; CASALI, V. W. D.; MORAES, C. F.; REGAZZI, A. J.; SILVA, E. A. M. Selfincompatibility in Passion Fruit (Passiflora edulis Sims). Acta Horticulturae, Wageningen, v. 370, p.4557, 1995.

CAMILLO, E. Polinização do maracujá. Ribeirão Preto: Ed. Holos, 2003. 44p.
CEREDA, E.; URASHIMA, A. S. Estudo comparativo do florescimento em ramos podados e não podados no maracujazeiro Passiflora edulis f. flavicarpa Deg. In: CONGRESSO BRASILEIRO DE FRUTICULTURA, 10, 1989, Fortaleza, CE. Anais....Fortaleza: SBF, 1989. p.379-385.

COBERT, S. A.; WILLMER, P. G. Pollination of the yellow passionfruit: nectar, pollen and carpenter bees. Journal of Agricultural Science, Cambridge, v. 95, p. 655-666, 1980.

CODEVASF. Projeto maniçoba. Disponível em: <www.codevasf.gov.br>. Acesso em: 24 jul. 2005

DAFNI, A. Pollination ecology: a practical approach (the practical approach series). New York: University Press, 1992. 250 p.

DEGENER, O. Passifloraceae. In: DEGENER, O. Flora hawaiiensis. Hardcover, 1933. (Book, 3).

EMBRAPA. Dados metereológicos. Juazeiro, BA: Estação Agrometereológica de Maniçoba. Disponível em: < www.cpatsa.embrapa.br>. Acesso em: 02 out. 2007.

GAGliAnONE, M. C.; HOFFMANN, M. Polinizadores do maracujá-amarelo no norte fluminense. In: ENCONTRO SOBRE ABELHAS, 7., 2006, Ribeirão Preto. Anais... v.1, p. 1-17.

GOTTSBERGER, G.; CAMARGO, J. M. F.; SILBERBAUER-GOTTSBERGER, I. A bee-pollinated tropical community: the beach dune vegetation of Ilha de São Luiz, Maranhão, Brazil. Botanische Jahrbücher für Systematik, Stutgard, v. 109, p. 469500,1988 .

INOUYE, D. W. The terminology of floral larceny. Ecology, New York, v. 61, n. 5, p. 1251-1253, 1980.

KEARNS, C. A.; INOUYE, D. W. Techniques for pollination biologists. Niwot, Colorado: University Press, 1993. 559p.

KIILL, L. H. P.; SIQUEIRA, K. M. M. de (Coord.). Diagnóstico de polinizadores no Vale do São Francisco: estratégias de manejo de polinizadores de fruteiras no Sub-Médio do Vale do São Francisco. Petrolina: Embrapa Semi-Árido; PROBIO, 2006. CDROM 
KILliP, E. P. The American species of Passifloraceae. Chicago: Field Museum of Natural History, 1938. 613p. (Botanical Series, 19)

KLEIN, A. M.; VAISSIÈRE, B. E.; CANE, J. H.; DEWENTER, I. S.; CUNNINGHAM, S. A.; KREMER, C.; TSCHARNTKE, T. Importance of pollinators in changing landscapes for world crops. Proceedings of the Royal Society B, Mosman, v. 274, p. 303-313, 2006.

KOSCHNITZKE, C. Morfologia e Biologia floral de cinco espécies de Passiflora L. (Passifloraceae). 1993. 81 f. Dissertação (Mestrado) - Universidade Estadual de Campinas, Campinas, 1993.

OLIVEIRA, P. E. Sustainable management of pollinators and passion fruit (Passiflora edulis F. flavicarpa DEG.) productions in Central Brazil. In: . In: ENCONTRO SOBREABELHAS, 7., 2006, Ribeirão Preto. Anais... v.1, p. 9-10.

RADFORD, A. E.; DICKISON, W. C.; MASSEY, J. R.; BELL, C. R. Vascular plant systematics. New York: Harper and Row, 1974.

ROJAS, G. G.; MEDINA, V. M. Vingamento de frutos do maracujazeiro-amarelo. Revista Brasileira de Fruticultura, Jaboticabal, v. 18, n. 2, p. 283-288, 1996.

RUGGIERO, C.; CORRÊA, L. S. Propagação do maracujazeiro. In: SIMPÓSIO SOBRE A CULTURA DO MARACUJAZEIRO, 2., 1978, Jaboticabal, Anais... Jaboticabal: FCAV, 1978. p.24-29.

RUGGIERO, C. Tratos culturais. In: RUGGIERO, C. (Ed.). Maracujá. Ribeirão Preto: Legis Summa, 1987. p. 58-66.

SAZIMA, I.; SAZIMA, M. Mangangavas e irapuás (Hymenoptera, Apoidea): visitas, interações e consequências para polinização do maracujá (Passifloraceae). Revista Brasileira de Entomologia, São Paulo, v. 33, n. 1, p. 109-118, 1989.

SEMIR, J.; BROWN JR.; K. S. Maracujá: a flor da paixão. Revista Geográfica Universal, Rio de Janeiro, v.2, n.5, p.40-47, 1975.

SILVA, M. M.; BUCKNER, C. H.; PICANÇO, M.; CRUZ, C. D. Influência de Trigona spinipesFabr. (Hymenoptera: Apidae) na polinização do maracujazeiro-amarelo. Anais da Sociedade Entomológica do Brasil, Piracicaba, v. 26, n. 02, p.217$221,1997$.

SILVA, M. M.; BUCKNER, C. H.; PICANÇO, M.;\& MOLINA-RUGAMA, A. J. Número floral, clima, densidad poblacional de Xilocopa spp. (Hymenoptera: Anthophoridae) y polinizacíon del maracuyá (Passiflora edulis f. flavicarpa). Revista de Biologia Tropical, Costa Rica, v. 47, n. 4, p. 711$718,1999$.

STATSOFT. STATISTICA (data analysis software system) version 6. 2003.

VARASSIN, I. G.; SILVA, A. G. A melitofilia em Passiflora alata Dryander (Passifloraceae), em vegetação de restinga. Rodriguésia, Rio de Janeiro, v. 50, n.76/77, p. 5-17, 1999.

ZANELLA, F. C. V.; MARTINS, C. F. Abelhas da Caatinga: biogeografia, ecologia e conservação. In: LEAL, I.R.; TABARELL, M.; SILVA, J.M.C. (Org.). Ecologia e conservação da caatinga. Recife: Editora Universitária, UFPE, 2003. p. 75-134.

ZEISLER, M. Über die Abgrenzung der eigentlichen Narbenfläche mit Hilfe von Reaktionen. Beihefte zum Botanische Zentralblatt, Cassel, v. 58, p. 308-318, 1938. 